appear to be significantly broader than the other resonances. Thus, the low-temperature spectra (Figure 1) give no evidence of freezing out of a "classical" norbornyl cation. This means only that if one views the spectra in terms of rapidly equilibrating classical ions, the barrier of that equilibration must be lower than about $3 \mathrm{kcal}$ $\mathrm{mol}^{-1}$. Within this limitation, one can adopt a different view. The recent studies of the appropriately deuterium labeled norbornyl cation by Saunders show very small isotopic splittings owing to perturbation of symmetry. ${ }^{15}$ This result is stronger support, albeit less direct, for the "nonclassical" symmetrical norbornyl cation. We anticipate that we shall be able to conduct MAS ${ }^{13} \mathrm{C}$ NMR spectroscopy in the $30 \mathrm{~K}$ range in the future and look forward to additional studies of this and other cations over this extended temperature range.

Acknowledgment. We thank the National Science Foundation for financial support (Industry/University Cooperative Program, Grant CHE-8020743) and IBM Instruments, Inc., for postdoctoral support (V.K.M.). The skilled assistance of R. D. Kendrick is gratefully acknowledged. We thank Dr. J. R. Lyerla for his interest and help in this work and Professor Martin Saunders for stimulating discussions.

Registry No. 2-Norbornyl cation, 24321-81-1.

(15) Saunders, M. A.; Kates, M. R. J. Am. Chem. Soc. 1980, 102, 6867.

\section{Stable Vinyl Cations. Direct Spectroscopic Observation of Vinyl-Substituted Vinyl Cations}

Hans-Ulirich Siehl*

\author{
Institut für Organische Chemie \\ der Universität Tübingen, $D-7400$ Tübigen \\ Federal Republic of Germany
}

Herbert Mayr*

\section{Institut für Organische Chemie der Universität Erlangen-Nürnberg D-8520 Erlangen, Federal Republic of Germany Received September 8, 1981}

Vinyl cations, although well established as reactive intermediates $^{1 \mathrm{a}}$ and predicted to be rather stable thermodynamically, ${ }^{16}$ have been rather elusive toward direct spectroscopic observation. Attempts to generate vinyl cations via $\mathrm{SbF}_{5}$-assisted heterolysis of $\alpha$-arylvinyl halides resulted in attack of $\mathrm{SbF}_{5}$ at the alkene $\pi$ system and formation of $\sigma$ complexes. ${ }^{2}$ Protonation of alkynes under strongly acidic conditions also failed to give stable vinyl cation solutions; ${ }^{3}$ rapid inter ${ }^{4}$ and intramolecular ${ }^{5}$ sequential reactions took place instead. Hitherto the only spectroscopic evidence comes from treatment of $\alpha$-alkynyl alcohols with superacids, leading to alkynylcarbenium ions, which may be regarded as vinyl cations if the allenic resonance structure is important. ${ }^{6}$

(1) (a) Stang, P. J.; Rappoport, Z.; Hanack, M.; Subramanian, L. R. "Vinyl Cations"; Academic Press: New York, 1979. (b) Mayr, H.; Schneider,

R.; Wilhelm, D.; Schleyer, P. v. R. J. Org. Chem., in press.

(2) Siehl, H.-U.; Hanack, M. J. Am. Chem. Soc, 1980, 102, 2686.

(3) Ferrocenyl-stabilized vinyl cations are accessible in this way and have been characterized by ${ }^{1} \mathrm{H}$ NMR spectroscopy: Abram, T. S.; Watts, W. E. J. Chem. Soc., Perkin Trans. I 1977, 1522.

(4) Olah, G. A.; Staral, J. S.; Spear, R. J.; Liang, G. J. Am. Chem. Soc. $1975,97,5489$.

(5) Olah, G. A.; Mayr, H. J. Am. Chem. Soc. 1976, 98, 7333; 1978, 100 , 6544

(6) Richey, H. G., Jr.; Philips, J. C. Rennick, L. E. J. Am. Chem. Soc. 1965, 87, 1381. Richey, H. G. Jr.; Rennick, L. E.: Kushner, A. S.; Richey J. M.; Philips, J. C. Ibid. 1965, 87, 4017. Pittman, C. U., Jr.; Olah, G. A. Ibid. 1965, 87, 5632. Olah, G. A.; Spear, R. J.; Westerman, P. W.; Denis, J.-M. Ibid. 1974, 96, 5855.

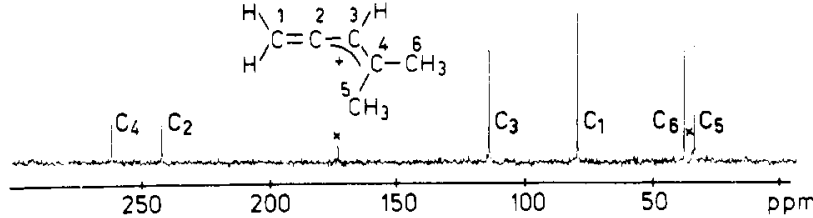

Figure 1. ${ }^{13} \mathrm{C}$ NMR spectrum of cation $3 \mathrm{a}$ in $\mathrm{SO}_{2} \mathrm{ClF} / \mathrm{SO}_{2} \mathrm{~F}_{2}(2: 1)$ at $-120^{\circ} \mathrm{C}$. Peaks marked $x$ are due to $\mathrm{CD}_{3} \mathrm{COCl}$ used as capillary lock.

We now report the first generation and NMR spectroscopic observation of $\alpha$-vinyl-substituted vinyl cations 3, which have previously been encountered as short-lived intermediates.

Grob and Spaar studied solvolysis reactions of 2-bromo-1,3butadienes and found particularly large rate enhancements through methyl groups at $C_{4}$, in accord with intermediate vinyl cations $\mathbf{3}^{\prime} \leftrightarrow 3^{\prime \prime}$ ? Reactions of $\alpha$-allenyl alcohols 2 with aqueous acid<smiles>CC(C)=C(C)C(Br)=C(C)C</smiles>

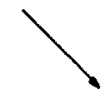<smiles>CC(C)=CC(C)=C(C)C</smiles><smiles>[CH]C(C)=C=C(C)C</smiles>

to give $\alpha, \beta$-unsaturated ketones were also suggested to proceed via vinyl cations $3 .^{8}$ Since conjugated double bonds are more stable than cumulated double bonds, vinyl cations 3 can be expected to form more readily from 2 than from 1 .

Clean solutions of $3 a-c$ in $\mathrm{SO}_{2} \mathrm{ClF} / \mathrm{SO}_{2} \mathrm{~F}_{2}$ were obtained by reaction of alcohols $2 \mathrm{a}-\mathbf{c}^{\mathbf{9}}$ with $\mathrm{SbF}_{5}$ using Saunders' 'molecular beam" method. ${ }^{10}$ The ${ }^{13} \mathrm{C}$ NMR spectra (Table I) were recorded at $-120^{\circ} \mathrm{C}$ and assigned by off-resonance and proton-coupled spectra (Figure 1). Single-frequency proton-decoupled spectra were used to confirm the assignments.

In all cations, $\mathrm{C}_{2}$ and $\mathrm{C}_{4}$ absorb at very low field, indicating location of positive charge at these positions. Contribution of both resonance structures $3^{\prime}$ and $3^{\prime \prime}$ is thus confirmed. The small chemical shift difference between $C_{3}$ in 3 and 2 shows that this position does not carry significant charge. The $C_{1}$ resonances are also quite similar in cations 3 and precursors 2 , since the $\mathrm{C}_{1} \mathrm{C}_{2}$ $\pi$ system cannot interact with the electron-deficient orbital at $\mathrm{C}_{2}$. Hindered rotation around the $\mathrm{C}_{3}-\mathrm{C}_{4}$ bond is responsible for the nonequivalence of $\mathrm{C}_{5}$ and $\mathrm{C}_{6}$.

Small, but significant, effects on chemical shifts are generated by methyl substitution at $\mathrm{C}_{1}$. The shift of $\mathrm{C}_{1}$ corresponds to the normal $\alpha^{\sigma}-\mathrm{CH}_{3}$ effect in allenes $\left(\simeq 10 \mathrm{ppm} / \mathrm{CH}_{3}\right.$ group ${ }^{11}$ and is almost identical for alcohols $2 \mathrm{a}-\mathbf{c}$ and cations $3 \mathrm{a}-\mathbf{c}$. While $\mathrm{C}_{3}$ is practically unaffected by $C_{1}$ substituents, the chemical shifts of $\mathrm{C}_{2}$ and $\mathrm{C}_{4}$ show opposite trends in series 2 and 3 . In the alcohols $2, \mathrm{C}_{1}$-methyl groups exert the normal $\beta^{\star}-\mathrm{CH}_{3}$ effect on $\mathrm{C}_{2}(\simeq-3$ $\mathrm{ppm} / \mathrm{CH}_{3}$ group) in allenes ${ }^{11}$ and do not influence the remote $\mathrm{C}_{4}$. In cations 3 , however, $\mathrm{C}_{2}$ is deshielded and $\mathrm{C}_{4}$ is shielded by methyl groups at $\mathrm{C}_{1}$. $\mathrm{CC}$ hyperconjugation, which is more effective than $\mathrm{CH}$ hyperconjugation, can account for this effect since the $\mathrm{C}_{1}-\mathrm{CH}_{3}$ bond is ideally oriented (dihedral angle of $0^{\circ}$ ) for interaction with

(7) Grob, C. A - Spaar, R Helv, Chim. Acta 1970, 53, 2119.

(8) Gelin, R.; Gelin, S.; Albrand, M. Bull. Soc. Chim. Fr. 1972, 720. Olsson, L.-I.; Claesson, A.; Bogentoft, C. Acta Chem. Scand. 1973, $27,1629$.

(9) Alcohols $2 a-c$ were prepared by a standard procedure: Cowie, J. S. Landor, P. D. Landor, S. R. J Chem. Soc., Perkin Trans. 1, 1973, 720. (10) Saunders, M.; Cox, D.; Lloyd, J. R. J. Am. Chem. Soc. 1979, 101, 6656.

(11) Stothers, J. B. "Carbon-13NMR Spectroscopy"; Academic Press: New York, 1972; p 76. 
Table I. ${ }^{13} \mathrm{C}$ NMR Chemical Shifts of Vinyl Cations 3a-c and Their Precursors 2a-ca

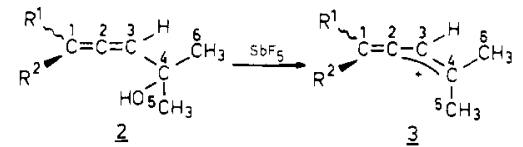

\begin{tabular}{|c|c|c|c|c|c|c|c|c|c|}
\hline compd & $\mathrm{R}^{1}$ & $\mathrm{R}^{2}$ & $C-1$ & $\mathrm{C}-2$ & $\mathrm{C}-3$ & C- -4 & $C-5$ & $C-6$ & $\mathrm{C}_{1}-\mathrm{CH}_{3}$ \\
\hline $3 a$ & $\mathbf{H}$ & $\mathrm{H}$ & 79.01 & 241.88 & 113.68 & 261.58 & 32.81 & 36.91 & \\
\hline $3 b$ & $\mathrm{CH}_{3}$ & $\mathrm{H}$ & 90.34 & 243.97 & 114.43 & 259.16 & 32.64 & 36.63 & 9.46 \\
\hline $3 c$ & $\mathrm{CH}_{3}$ & $\mathrm{CH}_{3}$ & 101.55 & 245.39 & 113.97 & 257.64 & 32.43 & 36.44 & 16.29 \\
\hline $2 a$ & $\mathrm{H}$ & $\mathrm{H}^{\circ}$ & 77.28 & 205.24 & 99.90 & 68.89 & \multicolumn{2}{|c|}{29.33} & \\
\hline $2 b$ & $\mathrm{CH}_{3}$ & $\mathbf{H}$ & 88.55 & 201.28 & 100.39 & 69.36 & $29.52^{b}$ & $29.59^{b}$ & 13.99 \\
\hline $2 c$ & $\mathrm{CH}_{3}$ & $\mathrm{CH}_{3}$ & 97.86 & 197.92 & 99.01 & 69.54 & \multicolumn{2}{|c|}{29.51} & 20.10 \\
\hline
\end{tabular}

${ }^{a}$ Specific assignments of $\mathrm{C}-5$ and $\mathrm{C}-6$ in the ions 3a-c tentatively analogous to allyl cations. $b$ Assignment tentative.

Table II. Calculated Bond Lengths $(\AA)$ and $\pi$ Densities $\rho$ of Vinyl Cations $3^{a}$

\begin{tabular}{ccccccc}
\hline compd & $\mathrm{C}^{1}-\mathrm{C}^{2}$ & $\mathrm{C}^{2}-\mathrm{C}^{3}$ & $\mathrm{C}^{3}-\mathrm{C}^{4}$ & $\rho_{2}$ & $\rho_{3}$ & $\rho_{4}$ \\
\hline 3a & 1.285 & 1.352 & 1.410 & 0.543 & 1.162 & 0.458 \\
3b & 1.287 & 1.358 & 1.403 & 0.518 & 1.167 & 0.481 \\
3c & 1.289 & 1.363 & 1.398 & 0.496 & 1.171 & 0.500 \\
\hline
\end{tabular}

${ }^{a}$ All calculations were carried out with the Gaussian 76 series of programs $^{14}$ at the STO-3G basis set level. ${ }^{15} \mathrm{C}-\mathrm{C}$ bond lengths were optimized; standard values were selected for angles and $\mathrm{C}-\mathrm{H}$ bond lengths.

the electron-deficient orbital at $\mathrm{C}_{2}{ }^{12}$ If corrections for the precursors are considered, 10.8-ppm deshielding of $\mathrm{C}_{2}$ and 4.6-ppm shielding of $\mathrm{C}_{4}$ can be attributed to the hyperconjugative electron donation of two methyl groups at $\mathrm{C}_{1}$. As in ordinary allyl cations, electron donation at one end increases the positive charge at this terminus $\left(C_{2}\right)$ and decreases the charge at the opposite end $\left(C_{4}\right)^{13}$

This interpretation of spectroscopic data is supported by ab initio MO calculations ${ }^{17}$ (Table II). The optimized bond lengths show that $\mathrm{C}_{1}-\mathrm{C}_{2}$ is identical with that in allene $(1.288 \AA){ }^{16}$ whereas $\mathrm{C}_{2}-\mathrm{C}_{3}$ and $\mathrm{C}_{3}-\mathrm{C}_{4}$ are similar as in allyl cations, ${ }^{13}$ in accord with the delocalized structure 3 . The positive charge is located at $\mathrm{C}_{2}$ and $\mathrm{C}_{4}$, the termini of the allylic cation.

Hyperconjugative electron donation by $C_{1}$ methyl groups is also confirmed by the calculations. As derived from the ${ }^{13} \mathrm{C}$ NMR spectra, electron density increases at $C_{4}$ and decreases at $C_{2}$ when methyl groups are added at $\mathrm{C}_{1}$. Simultaneously elongation of $\mathrm{C}_{2}-\mathrm{C}_{3}$ and shortening of the $\mathrm{C}_{3}-\mathrm{C}_{4}$ bond takes place. In valence bond terminology the contribution of resonance structure $3^{\prime}$ increases from $3 a$ to $3 \mathrm{c}$. Calculated $\pi$ densities indicate similar charge distributions in cation 3a and allyl cation $4^{13}$ This is verified by the similarity of the ${ }^{13} \mathrm{C}$ chemical shifts of the tertiary carbons in both species. The other carbons cannot directly be compared, since they are differently hybridized.

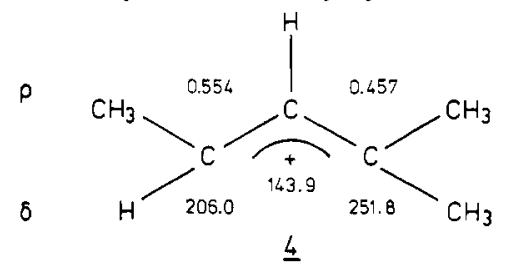

As part of an allene unit, $C_{3}$ and $C_{2}$ absorb at higher or lower field, respectively, than the corresponding allyl carbons of $4 . C_{2}$

(12) Apeloig, Y.; Schleyer, P. v. R.; Pople, J. A. J. Am. Chem. Soc. 1977 99.5901

(13) Mayr, H.; Förner, W.; Schleyer, P. v. R. J. Am. Chem. Soc. 1979, 101,$6032 ; 1980,102,3663$.

(14) Binkley, J. S.; Whiteside, R. A.; Hariharan, P. C.; Seeger, R.; Pople, J.; Hehre, W. J.; Newton, M. P. QCPE, Program No. 368, Indiana University.

(15) Hehre, W. J.; Stewart, R. F.; Pople, J. A. J. Chem. Phys. 1969, 51, 2657

(16) Radom, L.; Lathan, W. A.; Hehre, W. J.; Pople, J. A. J. Am. Chem Soc. $1971,93,5339$

(17) For MO calculations of the unsubstituted and monomethyl-substituted cations, see: Mirejovsky, D.; Drenth, W.; Duijneveldt, F. B. v. Recl. Trav. Chim. Pays-Bas. 1979, 98, 388. in $3 a-c$ is, to our knowledge, the most deshielded sp hybridized carbon reported so far for carbocations. Experiment and theory are thus in good agreement concerning the delocalized structure of vinyl cations $3 \mathbf{a}-\mathbf{c}$.

Acknowledgment. Support of the Deutsche Forschungsgemeinschaft to H.U.S. and the Fonds der Chemischen Industrie to H.M. is gratefully acknowledged.

Registry No. 2a, 34761-53-0; 2b, 56037-78-6; 2c, 2424-45-5; 3a, $80375-40-2 ; 3 b, 80375-41-3 ; 3 c, 80375-42-4$

\section{Preparation, Structural Characterization, and Reactivity of $\left(\mathrm{PEt}_{3}\right)_{2}(\mathrm{CO}) \mathrm{Rh}-\mathrm{Co}(\mathrm{CO})_{4}$. A Quantitative Study of the Reversible Heterolytic Cleavage of the Polar Rh-Co Bond}

David A. Roberts, ${ }^{\text {la }}$ William C. Mercer, ${ }^{1 a}$ Susan M. Zahurak, ${ }^{1 a}$ Gregory L. Geoffroy, ${ }^{* 1 a}$ C. W. DeBrosse, ${ }^{1 \mathrm{a}}$ Marion E. Cass, ${ }^{\text {b }}$ and Cortlandt G. Pierpont*1b

Department of Chemistry, The Pennsylvania State University University Park, Pennsylvania 16802 and the University of Colorado Boulder, Colorado 80309 Received June 15, 1981

A large number of heteronuclear metal-metal bonded compounds have been prepared and characterized, but relatively few have had their chemistry explored and even less have been shown to express catalytic activity. ${ }^{2-4}$ This is surprising in view of the unique reactivity features which should accrue as a result of adjacent metals with differing sets of chemical properties. The lack of catalytic activity appears to be due in part to the absence of open coordination sites or easily dissociable ligands in the complexes examined and the fact that relatively few contain one of the more active second-row metals such as rhodium. Another problem inherent with low-valent metal-metal bonded complexes is their susceptibility to cleavage of the metal-metal bond during reaction. $2,5,6$ A number of examples of such cleavage reactions have been reported but little quantitative data are available. ${ }^{5-10}$ We describe herein the preparation and characterization of $\left(\mathrm{PEt}_{3}\right)_{2}(\mathrm{CO}) \mathrm{Rh}-\mathrm{Co}(\mathrm{CO})_{4}(1)$, a coordinatively unsaturated polar

(1) (a) Pennsylvania State University. (b) University of Colorado

(2) Roberts, D. A.; Geoffroy, G. L. In "Comprehensive Organometallic Chemistry"; Wilkinson, G., Stone, F. G. A., Abel, E. W., Eds.; Pergamon Press: Oxford, in press; Chapter 40.

(3) Gladfelter, W. L.; Geoffroy, G. L., Adv. Organomet. Chem. 1980, 18, 207.

(4) Vyazankin, N. S.; Razuvaev, G. A.; Kruglaya, O. A. Organomet. Chem. Rev. 1968, 3A, 323.

(5) Meyer, T. J. Prog. Inorg. Chem. 1975, 19, 1

(6) Vahrenkamp, H. Angew. Chem., Int. Ed. Engl. 1978, 17, 379

(7) Ellis, J. E. J. Organomet. Chem. 1975, 86, 1.

(8) Pearson, R. G.; Dehand, J. J. Organomet. Chem. 1969, 16, 485

(9) Davison, A.; Ellis, J. E. J. Organomet. Chem. 1972, 36, 113.

(10) (a) Burlitch, J. M. J. Am. Chem. Soc. 1969, 91, 4562. (b) Ibid. 1969, 91,4563 . 